\title{
A high sIL-2R/ferritin ratio is a useful marker for the diagnosis of lymphoma-associated hemophagocytic syndrome
}

\author{
Takahiro Tsuji • Taichi Hirano • Hiroshi Yamasaki • \\ Mayumi Tsuji • Hiroyuki Tsuda
}

Received: 2 June 2013 / Accepted: 3 October 2013 / Published online: 25 October 2013

(C) The Author(s) 2013. This article is published with open access at Springerlink.com

\begin{abstract}
Lymphoma-associated hemophagocytic syndrome (LAHS), which is the major subtype of adult-onset secondary hemophagocytic lymphohistiocytosis (HLH), has a poor outcome. Although the early diagnosis and treatment of LAHS contributes to a better outcome, the lack of mass formation and the absence of distinct lymph node enlargement often delay the diagnosis of underlying lymphoma. A recent study, which statistically analyzed HLH cases in the literature, showed that the serum soluble interleukin-2 receptor (SIL-2R)/ferritin ratio could be used as a marker to diagnosis of LAHS. To verify this finding, we retrospectively analyzed the laboratory findings of $21 \mathrm{pa}-$ tients with HLH (10 benign disease-associated HLH and 11 LAHS). No significant differences were observed in the levels of LDH or CRP levels. The mean sIL-2R levels (units per milliliter) were significantly higher in the LAHS group $(4,176$ vs. $13,451, p=0.0031$ ), and ferritin levels (nanogram per milliliter) were higher in the benign disease-associated HLH group $(20,462$ vs. $2,561, p=0.0031)$. Consequently, the mean serum sIL-2R/ferritin ratio of patients with LAHS was markedly higher than that of patients with benign disease-associated HLH (0.66 vs. $8.56, p=0.0004)$. Thus, the results of this study demonstrated that the serum sIL-2R/ferritin ratio is a very useful marker for diagnosing of LAHS, which was further supported by clinical case analysis. Further studies to clarify the pathophysiology of secondary HLH caused by various triggers are needed.
\end{abstract}

Keywords Lymphoma-associated hemophagocytic syndrome . Malignant lymphoma $\cdot$ Soluble interleukin-2 receptor $\cdot$ Ferritin

T. Tsuji $(\bowtie) \cdot$ T. Hirano $\cdot$ H. Yamasaki $\cdot$ H. Tsuda

Division of Hematology and Oncology, Kumamoto City Hospital,

Kotoh 1-1-60, Kumamoto 862-8505, Japan

e-mail: tsuji.takahiro@city.kumamoto.lg.jp

M. Tsuji

Department of Environmental Health, University of Occupational and Environmental Health, 1-1 Iseigaoka, Yahatanishi-ku, Kitakyusyu 807-8555, Japan

\section{Introduction}

Hemophagocytic lymphohistiocytosis (HLH) is a clinicopathological entity characterized by the increased proliferation of benign macrophages that phagocytose blood cells throughout the reticuloendothelial system [1]. HLH has been classified into two distinct forms: primary or familial HLH and secondary HLH. Secondary HLH is an etiologically heterogeneous entity that has been associated with infections, autoimmune disorders, drugs, and malignant disease, typically malignant lymphoma [2-4]. Lymphomaassociated hemophagocytic syndrome (LAHS) is a subtype that accounts for approximately $40 \%$ of adult-onset secondary HLH and has a poor outcome [5]. Although the early diagnosis of underlying conditions, especially malignant lymphoma, leads to a better outcome, the diagnosis of LAHS is often difficult because of the frequent lack of mass formation and absence of distinct lymph node enlargement, which results in the development of progressive disease with an unfavorable prognosis. Tabata et al. reviewed Japanese patients in the literature and proposed that the serum soluble interleukin-2 receptor (sIL-2R)/ferritin ratio could be a useful marker for predicting underlying malignant lymphoma in HLH patients [6]. Here, we evaluated the serum sIL-2R/ferritin ratios of HLH patients in our institution to confirm its utility in differentiating LAHS from other reactive HLH.

\section{Methods}

Patients and methods

We retrospectively collected data on 21 patients who were diagnosed with HLH (benign disease-associated HLH and LAHS) between 2000 and 2011 at the Kumamoto City Hospital. Data collected on each patient included age, presumed 
etiology, presence or absence of splenomegaly, white blood cell (WBC), absolute neutrophil count (ANC), hemoglobin $(\mathrm{Hb})$, platelet (PLT), aspartate aminotransferase (AST), alanine aminotransferase (ALT), lactate dehydrogenase (LDH), triglycerides (TG), fibrinogen (Fib), C-reactive protein (CRP), sIL-2R, ferritin, nuclear cell count (NCC), and percentage of macrophages in the bone marrow. HLH was diagnosed according to the HLH-2004 diagnostic guidelines [7]. Five of the following eight criteria had to be fulfilled: (1) fever; (2) splenomegaly; (3) cytopenia affecting at least two of three lineages in the peripheral blood; (4) hypertriglyceridemia (triglycerides of $\geq 265 \mathrm{mg} / \mathrm{dl}$ ) and/or hypofibrinogenemia (fibrinogen of $\leq 150 \mathrm{mg} / \mathrm{dl}$ ); (5) hemophagocytosis in the bone marrow, spleen, or lymph nodes; (6) low or absent NK cell activity; (7) hyperferritinemia (ferritin of $\geq 500 \mu \mathrm{g} / \mathrm{l}$ ); and (8) high levels of sIL-2R $(\geq 2,400 \mathrm{U} / \mathrm{ml})$. The diagnosis of malignant lymphoma was made according to the 2008 WHO classification [8]. We compared the laboratory findings (WBC, ANC, Hb, PLT, AST, ALT, LDH, CRP, ferritin, sIL-2R, and sIL-2R/ferritin ratio) of the benign disease-associated HLH group with those of the LAHS group. The nonparametric Mann-Whitney $U$ test was used to compare the values of the two groups. In all tests, a $p$ value of $<0.05$ was considered significant.

\section{Results}

\section{Clinical features}

A total of 21 patients were included in this analysis. The clinical characteristics of these patients are described in Tables 1,2, 3, and 4. Benign disease-associated HLH was diagnosed in 10 patients (case B1-10 in Tables 1 and 2; benign disease- associated HLH group), and LAHS in 11 patients (case L1-11 in Tables 3 and 4; LAHS group).

The median age of the benign disease-associated HLH group (Tables 1 and 2) was 43.6 years, ranging between 17 and 68 years. The etiologic subtypes were infection (pneumonia, $n=1$; Epstein-Barr virus, $n=1$; cytomegalovirus, $n=1$; and malaria, $n=2$ ), and autoimmune disorders (adult-onset Still's disease (AOSD), $n=2$ ). The underlying cause could not be determined in two patients (cases B1 and B5) in spite of tests being performed for the Epstein-Barr virus, cytomegalovirus, parvovirus, virus hepatitis (hepatitis $\mathrm{A}, \mathrm{B}$, and $\mathrm{C}$ ), sepsis, autoimmune disorders, drugs, and malignancy. Both patients recovered with short-term immunosuppressive therapy (case B1, corticosteroid + cyclosporine; case B5, corticosteroid), and recurrences was not observed.

The median age of the LAHS group (Tables 3 and 4) was 72.0 years, ranging between 56 and 98 years. The most frequent histopathological subtype was intravascular large B cell lymphoma (IVLBCL), Asian variant $(n=6)$, and diffuse large B cell lymphoma (DLBCL), not otherwise specified (NOS) ( $n=2$ ), followed by peripheral T cell lymphoma (PTCL), NOS $(n=2)$, and extranodal NK/T cell lymphoma, nasal type (ENKL) $(n=1)$. All patients in the LAHS group were clinical stage IVB, and bone marrow involvement was observed in nine patients. According to the International Prognostic Index, all patients were categorized as high risk. Neither a distinct tumor mass nor apparent lymph node enlargement was noted in six patients (cases L1, L2, L4, L6, L7, and L8), and lymphoma was diagnosed by bone marrow examination in four out of six patients. One patient (case L2) was diagnosed with lymphoma by autopsy, and one patient (case L6) was diagnosed with lymphoma by transbronchial lung biopsy (TBLB) and random skin biopsy.

Table 1 Clinical characteristics of patients with benign disease-associated HLH

\begin{tabular}{|c|c|c|c|c|c|c|c|c|c|c|c|c|c|}
\hline Case & Age & Sex & Cause & $\begin{array}{l}\text { WBC } \\
(/ \mu \mathrm{l})\end{array}$ & $\begin{array}{l}\text { ANC } \\
(/ \mu \mathrm{l})\end{array}$ & $\begin{array}{l}\mathrm{Hb} \\
(\mathrm{g} / \mathrm{dl})\end{array}$ & $\begin{array}{l}\text { PLT } \\
(/ \mu \mathrm{l})\end{array}$ & $\begin{array}{l}\text { AST } \\
(\mathrm{U} / \mathrm{l})\end{array}$ & $\begin{array}{l}\text { ALT } \\
(\mathrm{U} / \mathrm{l})\end{array}$ & $\begin{array}{l}\text { LDH } \\
(/ \mathrm{UNL})\end{array}$ & $\begin{array}{l}\text { TG } \\
(\mathrm{mg} / \mathrm{dl})\end{array}$ & $\begin{array}{l}\text { Fib } \\
(\mathrm{mg} / \mathrm{dl})\end{array}$ & $\begin{array}{l}\text { CRP } \\
(\mathrm{mg} / \mathrm{dl})\end{array}$ \\
\hline B1 & 17 & M & Unknown & 2,400 & 384 & 11.0 & 6.5 & 2,090 & 2,590 & 11.8 & n.t. & 198 & 0.5 \\
\hline B2 & 62 & $\mathrm{~F}$ & $\begin{array}{l}\text { Erythema exsudativum } \\
\text { multiforme }\end{array}$ & 3,400 & 1,700 & 12.7 & 10.5 & 368 & 307 & 3.1 & 199 & 162 & 0.4 \\
\hline B3 & 52 & M & Pneumonia & 2,400 & 1,176 & 13.5 & 4.2 & 427 & 328 & 4.2 & n.t. & 415 & 19.9 \\
\hline B4 & 31 & M & CMV & 3,500 & 1,820 & 13.6 & 4.2 & 91 & 61 & 5.0 & n.t. & 478 & 23.6 \\
\hline B5 & 50 & $\mathrm{~F}$ & Unknown & 600 & 189 & 11.2 & 5.4 & 6,300 & 3,400 & 32.3 & 157 & 134 & 7.4 \\
\hline B6 & 50 & M & EBV & 5,300 & 2,730 & 13.8 & 10.8 & 203 & 353 & 2.2 & n.t. & 333 & 3.1 \\
\hline B7 & 41 & M & Malaria & 4,100 & 1,353 & 10.4 & 7.6 & 60 & 73 & 2.0 & 729 & 574 & 14.2 \\
\hline B8 & 33 & M & Malaria & 2,600 & 1,300 & 10.7 & 4.3 & 40 & 74 & 1.4 & 310 & 456 & 19.8 \\
\hline B9 & 68 & F & AOSD & 2,400 & 984 & 9.2 & 13.9 & 57 & 37 & 1.4 & 123 & 276 & 1.2 \\
\hline B10 & 32 & $\mathrm{~F}$ & AOSD & 13,800 & 12,765 & 11.6 & 4.3 & 1,978 & 1,820 & 17.5 & 239 & 188 & 3.8 \\
\hline
\end{tabular}

$A N C$ absolute neutrophil count, $T G$ triglyceride, $F i b$ fibrinogen, $C M V$ cytomegalovirus, $E B V$ Epstein-Barr virus, $A O S D$ adult-onset Still's disease, UNL upper normal limit, n.t. not tested 
Table 2 Clinical characteristics of patients with benign disease-associated HLH

\begin{tabular}{|c|c|c|c|c|c|c|c|c|}
\hline Case & Splenomegaly & $\begin{array}{l}\text { Hemophagocytosis } \\
\text { (bone marrow) }\end{array}$ & $\mathrm{NCC}(/ \mu \mathrm{l})$ & Histiocyte $(\%)$ & HLH-2004 & sIL2R (U/ml) & Ferritin (ng/ml) & sIL2R/ferritin \\
\hline B1 & + & + & $65.0 \times 10^{4}$ & 0.6 & $5(8)$ & 2,162 & 26,798 & 0.08 \\
\hline B2 & + & + & $3.0 \times 10^{4}$ & 1.6 & $5(8)$ & 2,704 & 11,775 & 0.22 \\
\hline B3 & + & + & $8.6 \times 10^{4}$ & 6.0 & $5(8)$ & 8,657 & 29,577 & 0.29 \\
\hline B4 & + & + & $7.0 \times 10^{4}$ & 2.6 & $5(8)$ & 3,660 & 11,174 & 0.32 \\
\hline B5 & + & + & $2.1 \times 10^{4}$ & 9.6 & $7(8)$ & 4,028 & 6,865 & 0.58 \\
\hline B6 & + & + & $3.0 \times 10^{4}$ & 1.0 & $5(8)$ & 2,416 & 882 & 2.73 \\
\hline B7 & + & n.t. & n.t. & n.t. & $5(8)$ & 2,563 & 6,947 & 0.37 \\
\hline B8 & + & n.t. & n.t. & n.t. & $5(8)$ & 3,222 & 2,746 & 1.17 \\
\hline B9 & + & + & $0.9 \times 10^{4}$ & 3.0 & $5(8)$ & 6,078 & 7,852 & 0.77 \\
\hline $\mathrm{B} 10$ & + & + & $6.0 \times 10^{4}$ & 3.4 & $5(8)$ & 6,271 & 100,000 & 0.06 \\
\hline
\end{tabular}

NCC nuclear cell count, n.t. not tested

\section{Laboratory findings}

The laboratory findings of the initial presentation are summarized in Tables 1 and 2 (case B1-10, the benign disease-associated HLH group) and Tables 3 and 4 (case L1-11, the LAHS group). All our patients fulfilled the required criteria for the diagnosis of $\mathrm{HLH}$. Although serum ferritin levels were under $1,000 \mathrm{ng} / \mathrm{ml}$ in four cases (cases L6, L7, L11, and B6), hemophagocytosis by activated macrophages was confirmed in the bone marrow.

One patient in the benign disease-associated HLH group $(10 \%)$ had anemia $(\mathrm{Hb} \leq 10.0 \mathrm{~g} / \mathrm{dl})$, while seven patients (70\%) had thrombocytopenia (PLT $\leq 100,000 / \mu 1)$. Other findings of interest were increased levels of LDH, ferritin, CRP, and sIL-2R in all patients examined. One patient had hypofibrinogenemia (fibrinogen of $\leq 150 \mathrm{mg} / \mathrm{dl}$ ), and two patients had hypertriglyceridemia (triglycerides of $\geq 265 \mathrm{mg} / \mathrm{dl}$ ).

Seven patients in the LAHS group (63.6\%) had anemia $(\mathrm{Hb} \leq 10.0 \mathrm{~g} / \mathrm{dl})$, while six patients $(54.5 \%)$ had thrombocytopenia $(\mathrm{PLT} \leq 100,000 / \mu \mathrm{l})$. LDH, CRP, ferritin, and sIL-2R levels were elevated in all patients. Although very high CRP was observed in two patients (cases L3 and L4), infection was not complicated in both these patients. Two patients had hypofibrinogenemia (fibrinogen of $\leq 150 \mathrm{mg} / \mathrm{dl}$ ), and one patient had hypertriglyceridemia (triglycerides of $\geq 265 \mathrm{mg} / \mathrm{dl}$ ).

Table 3 Clinical characteristics of patients with LAHS

\begin{tabular}{|c|c|c|c|c|c|c|c|c|c|c|c|c|c|c|c|c|}
\hline Case & Age & Sex & Cause & $\begin{array}{l}\text { Diagnosed } \\
\text { site }\end{array}$ & $\begin{array}{l}\text { Bone marrow } \\
\text { invasion }\end{array}$ & Stage & $\begin{array}{l}\text { WBC } \\
(/ \mu \mathrm{l})\end{array}$ & $\begin{array}{l}\text { ANC } \\
(/ \mu \mathrm{l})\end{array}$ & $\begin{array}{l}\mathrm{Hb} \\
(\mathrm{g} / \mathrm{dl})\end{array}$ & $\begin{array}{l}\text { PLT } \\
(/ \mu \mathrm{l})\end{array}$ & $\begin{array}{l}\text { AST } \\
(\mathrm{U} / 1)\end{array}$ & $\begin{array}{l}\text { ALT } \\
(\mathrm{U} / \mathrm{l})\end{array}$ & $\begin{array}{l}\text { LDH } \\
\text { (/UNL) }\end{array}$ & $\begin{array}{l}\text { Fib } \\
(\mathrm{mg} / \mathrm{dl})\end{array}$ & $\begin{array}{l}\text { TG } \\
(\mathrm{mg} / \mathrm{dl})\end{array}$ & $\begin{array}{l}\text { CRP } \\
(\mathrm{mg} / \mathrm{dl})\end{array}$ \\
\hline L1 & 73 & M & IVLBCL & Bone marrow & + & IVB & 4,100 & 3,342 & 10.8 & 7.6 & 25 & 19 & 1.7 & 213 & n.t. & 1.9 \\
\hline L2 & 67 & M & IVLBCL & Autopsy & + & IVB & 8,200 & 6,560 & 8.4 & 12.3 & 45 & 19 & 3.5 & 301 & 159 & 13.9 \\
\hline L3 & 98 & $\mathrm{~F}$ & $\begin{array}{l}\text { DLBCL, } \\
\text { NOS }\end{array}$ & Lymph node & Not detected & IVB & 3,800 & 2,413 & 8.9 & 13.4 & 34 & 9 & 6.7 & n.t. & n.t. & 29.3 \\
\hline L4 & 74 & $\mathrm{~F}$ & IVLBCL & Bone marrow & + & IVB & 4,200 & 1,953 & 7.6 & 16.6 & 58 & 25 & 2.5 & n.t. & n.t. & 17.3 \\
\hline L5 & 76 & M & $\begin{array}{c}\text { DLBCL, } \\
\text { NOS }\end{array}$ & Lymph node & + & IVB & 10,700 & 7,875 & 8.4 & 8.3 & 39 & 19 & 4.6 & 178 & n.t. & 9.0 \\
\hline L6 & 59 & $\mathrm{~F}$ & IVLBCL & Skin, lung & Not detected & IVB & 4,900 & 2,793 & 9.0 & 20.5 & 46 & 8 & 8.9 & 408 & 306 & 8.2 \\
\hline L7 & 77 & $\mathrm{~F}$ & IVLBCL & Bone marrow & + & IVB & 3,500 & 2,730 & 7.4 & 5.0 & 20 & 30 & 2.4 & 220 & n.t. & 3.0 \\
\hline L8 & 86 & F & IVLBCL & Bone marrow & + & IVB & 2,400 & 1,872 & 11.1 & 7.3 & 96 & 58 & 1.9 & 100 & 169 & 5.0 \\
\hline L9 & 56 & M & ENKL & Liver & + & IVB & 1,800 & 1,026 & 12.6 & 8.5 & 157 & 132 & 3.4 & 163 & 249 & 0.3 \\
\hline L10 & 62 & $\mathrm{~F}$ & $\begin{array}{l}\text { PTCL, } \\
\text { NOS }\end{array}$ & Lymph node & + & IVB & 2,900 & 2,523 & 10.7 & 8.5 & 142 & 60 & 3.0 & 99 & 211 & 10.1 \\
\hline L11 & 65 & $\mathrm{~F}$ & $\begin{array}{l}\text { PTCL, } \\
\text { NOS }\end{array}$ & Skin & + & IVB & 3,100 & 1,225 & 9.0 & 10.6 & 35 & 20 & 1.3 & 256 & n.t. & 1.1 \\
\hline
\end{tabular}

ANC absolute neutrophil count; TG triglyceride; Fib fibrinogen; IVBCL intravascular B cell lymphoma; DLBCL, NOS diffuse large B cell lymphoma, not otherwise specified; ENKL extranodal NK cell lymphoma; PTCL, NOS peripheral T cell lymphoma, not otherwise specified; $U N L$ upper normal limit; n.t. not tested 
Table 4 Clinical characteristics of patients with LAHS

\begin{tabular}{|c|c|c|c|c|c|c|c|c|}
\hline Case & Splenomegaly & Hemophagocytosis & $\mathrm{NCC}(/ \mu \mathrm{l})$ & Histiocyte (\%) & HLH-2004 & sIL-2R (U/ml) & Ferritin (ng/ml) & sIL-2R/ferritin \\
\hline L1 & + & + & $11.0 \times 10^{4}$ & 1.0 & $5(8)$ & 9,221 & 2,613 & 3.52 \\
\hline $\mathrm{L} 2$ & + & + & $6.4 \times 10^{4}$ & 2.4 & $5(8)$ & 9,793 & 3,273 & 2.99 \\
\hline L3 & + & + & Dry tap & 4.0 & $5(8)$ & 12,569 & 2,861 & 4.39 \\
\hline L4 & + & + & $17.0 \times 10^{4}$ & 1.6 & $5(8)$ & 4,291 & 1,729 & 2.48 \\
\hline L5 & + & + & $5.5 \times 10^{4}$ & 0.2 & $6(8)$ & 36,938 & 1,184 & 31.19 \\
\hline L6 & + & + & $4.4 \times 10^{4}$ & 2.0 & $6(8)$ & 3,462 & 718 & 4.82 \\
\hline L7 & + & + & $6.0 \times 10^{4}$ & 3.0 & $6(8)$ & 11,536 & 707 & 16.31 \\
\hline L8 & + & + & $1.0 \times 10^{4}$ & 1.0 & $6(8)$ & 36,715 & 3,477 & 10.55 \\
\hline L9 & + & + & $2.8 \times 10^{4}$ & 0.8 & $5(8)$ & 3,588 & 4,923 & 0.72 \\
\hline L10 & + & + & $7.0 \times 10^{4}$ & 0.4 & $6(8)$ & 10,230 & 6,067 & 1.68 \\
\hline L11 & + & + & $2.8 \times 10^{4}$ & 1.0 & $5(8)$ & 9,620 & 619 & 15.54 \\
\hline
\end{tabular}

NCC nuclear cell count

Comparison of laboratory findings between LAHS and benign disease-associated HLH

A comparison of laboratory findings between the LAHS and disease-associated HLH groups is shown in Table 5. There were no significant differences in LDH or CRP levels ( $p=0.53$ and $p=0.94)$. Neutropenia and thrombocytopenia were more severe in the benign disease-associated HLH group $(p=0.045$ and $p=0.045)$. Anemia was more severe in the LAHS group $(p=0.005)$. Liver enzymes in the benign disease-associated HLH were higher than those in the LAHS group. The mean sIL-2R levels were higher $(p=0.0031)$, and the mean ferritin levels were lower $(p=0.0031)$ in the LAHS group than those in the benign disease-associated HLH group, respectively (Table 5). Consequently, the mean serum sIL-2R/ferritin ratio of patients with LAHS was markedly higher than that of patients with benign disease-associated HLH (8.56 vs. $0.66, p=0.0004)$ (Table 5).

\section{Discussion}

Secondary HLH presents in a number of different clinical contexts with various etiologic associations. Patients typically have concurrent infections/medical conditions that appear to trigger their HLH, such as infection, malignancy, or autoimmune disorders [1-3]. In this study, we presented 21 secondary HLH cases diagnosed at a single institution. The major etiology of our cases was lymphoma, followed by infection (EBV, CMV, malaria), and AOSD. AOSD is a systemic inflammation disorder of unknown origin characterized by spiking fever, rash, polyarthralgia, and hyperferritinemia.

Table 5 Comparison of the laboratory findings of the two groups (benign disease-associated HLH and LAHS)

\begin{tabular}{|c|c|c|c|c|c|}
\hline & $\begin{array}{l}\text { Benign disease-associated HLH } \\
\text { Mean } \pm \text { SD } \\
n=10\end{array}$ & Range & $\begin{array}{l}\text { LAHS } \\
\text { Mean } \pm \mathrm{SD} \\
n=11\end{array}$ & Range & $p$ value \\
\hline WBC $(\times 109 / 1)$ & $4,050 \pm 1,152$ & $600-13,800$ & $4,509 \pm 799$ & $1,800-10,700$ & NS \\
\hline ANC $(\times 109 / 1)$ & $2,440 \pm 1,170$ & $189-12,765$ & $3,119 \pm 650$ & $1,026-7,875$ & $<0.05$ \\
\hline $\mathrm{Hb}(\mathrm{g} / \mathrm{dl})$ & $11.8 \pm 0.5$ & $9.2-13.8$ & $9.4 \pm 0.5$ & $7.4-12.6$ & $<0.01$ \\
\hline PLT $(\times 109 / 1)$ & $7.2 \pm 1.1$ & $4.2-13.9$ & $10.8 \pm 1.4$ & $5.0-20.5$ & $<0.05$ \\
\hline $\operatorname{AST}(\mathrm{U} / \mathrm{l})$ & $1,161 \pm 622$ & $40-6,300$ & $63.4 \pm 14.2$ & $20-157$ & $<0.01$ \\
\hline $\operatorname{ALT}(\mathrm{U} / \mathrm{l})$ & $904 \pm 391$ & $37-3,400$ & $36.3 \pm 10.9$ & $8-132$ & $<0.001$ \\
\hline LDH (/UNL) & $8.1 \pm 3.2$ & $1.4-32.3$ & $3.6 \pm 0.7$ & $1.3-8.9$ & NS \\
\hline CRP (mg/dl) & $9.4 \pm 2.9$ & $0.4-23.6$ & $9.0 \pm 2.6$ & $0.3-29.3$ & NS \\
\hline sIL-2R (U/ml) & $4,176 \pm 677$ & $2,162-8,657$ & $13,451 \pm 3,611$ & $3,462-36,938$ & $<0.005$ \\
\hline Ferritin (ng/ml) & $20,462 \pm 9,330$ & $882-100,000$ & $2,561 \pm 544$ & $619-6,067$ & $<0.005$ \\
\hline sIL-2R/ferritin & $0.66 \pm 0.25$ & $0.06-2.73$ & $8.56 \pm 2.79$ & $0.72-31.1$ & $<0.0005$ \\
\hline
\end{tabular}

$U N L$ upper normal limit, $N S$ not significant 
Macrophage activation syndrome (MAS) is a life-threatening complication of AOSD $[9,10]$. Clinically, patients with MAS present with high fever, pancytopenia, hepatosplenomegaly, hepatic dysfunction, encephalopathy, coagulation abnormalities, and sharply increased levels of ferritin. As MAS is clinically similar to HLH, it is currently classified among the secondary forms of HLH [8]. It is difficult to distinguish an AOSD flare from HLH/MAS because HLH/MAS and AOSD share several clinical features [11]. Preliminary diagnostic guidelines have been presented for MAS, which consisted of laboratory and clinical criteria [7]. There were two cases of AOSD-associated HLH (cases B9 and B10) in this study, and both of them satisfied the diagnostic criteria of MAS.

A Japanese survey revealed that LAHS was a major subtype in adult-onset HLH cases and had a poor outcome [5]. LAHS accounted for $43 \%$ of HLH patients older than 15 years of age and for $67 \%$ of patients older than 60 years of age [5]. Approximately $46 \%$ of patients with LAHS were associated with B cell lymphoma (B-LAHS), and approximately $32 \%$ with NK/T cell lymphoma (NK/T-LAHS) [5]. The predominant histology of B cell tumors was DLBCL (15\%) and IVLBCL (14\%), while PTCL (12\%) and ENKL (11 \%) were the major histologic subtypes noted among T/NK cell tumors [5]. Ishii et al. analyzed the outcome of a distinct subtype of HLH and showed that the 5 -year overall survival rates were $48.2 \%$ for BLAHS, $12.2 \%$ for NK/T-LAHS, $82.7 \%$ for Epstein-Barr virus-HLH, $89.0 \%$ for other infection-associated HLH, and $89.6 \%$ for autoimmune-associated HLH [5]. The lack of mass formation and absence of apparent lymph node enlargement often delays the diagnosis of LAHS, which results in the progression of the disease and an unfavorable prognosis. LAHS, especially IVLBCL with HLH, develops rapidly, and a diagnostic delay contributes to fatal outcome. IVLBCL accounts for $0.9 \%$ of all lymphomas in Japan (Okamoto et al. 2009) and is characterized by fever and hepatosplenomegaly without lymphadenopathy at initial presentation.

Tabata et al. reviewed 110 patients, including 57 LAHS cases and 53 benign disease-associated HLH cases in the literature, and demonstrated the important role of not only a high serum sIL-2R level $(\geq 5,000 \mathrm{U} / \mathrm{ml})$ but also a high sIL$2 \mathrm{R} /$ ferritin ratio $(\geq 2.0)$ in the diagnosis of LAHS [6]. In addition, they evaluated the positive predictive values of parameters for LAHS. The positive predictive value (PPV) for LAHS of high sIL-2R ( $\geq 5,000 \mathrm{U} / \mathrm{ml})$ was $81.0 \%$, and the PPV for LAHS of a high sIL-2R/ferritin ratio $(\geq 2.0)$ was $85.2 \%$ [6]. Moreover, the PPV of both parameters combined was $95.6 \%$ [6]. They then proposed that the serum sIL-2R/ ferritin ratio could be used as a useful marker to diagnosis of LAHS. However, variations in the normal ranges of SIL-2R and ferritin have been reported, depending on the various assays used in different laboratories. In addition, neither the clinical features of HLH patients nor the diagnostic criteria were shown in this study.
Therefore, we attempted to analyze the laboratory findings including parameters such as sIL-2R, ferritin, and sIL-2R/ ferritin in the HLH patients diagnosed in our institution to verify this study. Our results showed that the level of sIL-2R was significantly higher $(p=0.0031)$ and the ferritin level was lower $(p=0.0031)$ in the LAHS group than that in the benign disease-associated HLH group. Consequently, the mean serum sIL-2R/ferritin ratio of patients with LAHS was significantly higher than that of patients with benign diseaseassociated HLH $(p=0.0004)$ (Table 5). In the LAHS group, a high serum sIL-2R level $(\geq 5,000 \mathrm{U} / \mathrm{ml})$ and high sIL-2R/ ferritin ratio $(\geq 2.0)$ were observed in 8 and 9 out of 11 patients, respectively. In contrast, cases with a high serum sIL-2R level and high sIL-2R/ferritin ratio in the benign disease-associated HLH group were only 2 and 1 out of 10 patients, respectively.

The clinical features of each case further revealed the usefulness of these parameters. For example, the underlying disease of HLH in case L2 (Tables 3 and 4) was not diagnosed until IVBCL was confirmed by autopsy. The sIL-2R level and sIL-2R/ferritin ratio at the diagnosis of HLH were as high as 9 , $793 \mathrm{U} / \mathrm{ml}$ and 2.99, respectively. In case L6 (Tables 3 and 4) without lymphadenopathy or the bone marrow infiltration of tumor cells, only TBLB and random skin biopsy confirmed the presence of IVLBCL with HLH. Although the sIL-2R level was relatively low $(3,462 \mathrm{U} / \mathrm{ml})$, the $\mathrm{sIL}-2 \mathrm{R} /$ ferritin ratio was as high as 4.82 . On the other hand, the underlying cause of HLH in case B9 (Tables 1 and 2) was first suspected to be malignant lymphoma because of elevations in LDH, sIL-2R, and $\beta 2$ microglobulin levels and abnormal uptakes by an enlarged spleen on FDG-PET/CT scanning. Six months after the diagnosis of HLH, the patient exhibited a typical rash and arthralgia and was diagnosed with AOSD. At the diagnosis of $\mathrm{HLH}$, her sIL-2R level was less than 5,000 U/ml (4,733 U/ml), and sIL-2R/ferritin ratio was as low as 0.45 . Thus, both of these parameters, especially the latter, appear to be useful for predicting the presence of lymphoma in the background of HLH.

The pathogenesis of secondary HLH is not as well understood as that of primary HLH. However, secondary HLH is also characterized by a marked elevation in the serum level of sIL-2R and ferritin, both of which are the parameters of diagnostic criteria [7]. Hyperferritinemia generally reflects the activation of macrophages in HLH, while elevated levels of sIL-2R reflect $\mathrm{T}$ cell activation [10-12]. Relatively high sIL-2R and relatively low ferritin levels in LAHS result in a markedly high sIL-2R/ferritin ratio, which ratio may indicate excessive $\mathrm{T}$ cell activation related to the activation of macrophages in LAHS.

In summary, we evaluated the laboratory findings of HLH patients in our institution and recognized the utility of the sIL$2 \mathrm{R} /$ ferritin ratio for diagnosing LAHS. A high sIL-2R/ferritin ratio strongly indicates the presence of underlying malignant lymphoma. 
Conflict of interest We herein declare that there is no financial support or relationships that may pose conflict of interest.

Open Access This article is distributed under the terms of the Creative Commons Attribution License which permits any use, distribution, and reproduction in any medium, provided the original author(s) and the source are credited.

\section{References}

1. Janka GE (2007) Hemophagocytic syndromes. Blood Rev 21:245-253

2. Tsuda H (1997) Hemophagocytic syndrome (HPS) in children and adults. Int J Hematol 65:215-216

3. Imashuku S (1997) Differential diagnosis of hemophagocytic syndrome: underlying disorders and selection of the most effective treatment. Int J Hematol 66:135-151

4. Janka G, Imashuku S, Elinder G, Schneider M, Henter JI (1998) Infection- and malignancy-associated hemophagocytic syndromes. Secondary hemophagocytic lymphohistiocytosis. Hematol Oncol Clin North Am 12:435-444
5. Ishii E, Ohga S, Imasyuku S et al (2007) Nationwide survey of hemophagocytic lymphohistiocytosis in Japan. Int J Hematol 86:58-68

6. Tabata C, Tabata R (2012) Possible prediction of underlying lymphoma by high sIL-2R/ferritin ratio in hemophagocytic syndrome. Ann Hematol 91:63-71

7. Henter J-I, Horne AC, Arico M et al (2007) HLH-2004: diagnostic and therapeutic guidelines for hemophagocytic lymphohistiocytosis. Pediatr Blood Cancer 48:124-131

8. Swerdlow SH, Campo E, Harris NL et al (2008) WHO classification of tumours of haematopoietic and lymphoid tissues, 4th edn. Lyon, IARC

9. Ravelli A, Grom AA, Behrens EM, Cron RQ (2012) Macrophage activation syndrome as part of systemic juvenile idiopathic arthritis: diagnosis, genetics, pathophysiology and treatment. Genes Immun 13: 289-298

10. Ravelli A, Magni-Manzoni S, Pistorio A et al (2005) Preliminary diagnostic guidelines for macrophage activation syndrome complicating systemic juvenile idiopathic arthritis. J Pediatr 146:598-604

11. Hot A, Toh ML, Coppéré B et al (2010) Reactive hemophagocytic syndrome in adult-onset Still disease: clinical features and long-term outcome: a case control study of 8 patients. Medicine (Baltimore) 89: $37-46$

12. Fujiwara F, Hibi S, Imashuku S (1993) Hypercytokinemia in hemophagocytic syndrome. Am J Pediatr Hematol Oncol 15:92-98 